\title{
BILHETES DO CÁRCERE: elo entre espaços
}

\author{
Temis Gomes Parente*
}

Valcelir Borges da Silva**

\section{Resumo}

O mundo do cárcere tem sido objeto de variados estudos nas mais diversas áreas e ainda assim permanece muito pouco conhecido, sobretudo pelas barreiras que se impõem ao pesquisador para obter contato direto com os presos e com fontes primárias. Nesse sentido, o presente trabalho tem o diferencial de apresentar uma análise de 960 bilhetes escritos por homens presos da Casa de Prisão Provisória de Palmas, realizada durante a nossa pesquisa de mestrado em Ciências do Ambiente pela Universidade Federal do Tocantins (UFT). O artigo propõese a apresentar uma interpretação sobre o cotidiano da prisão; buscamos, de maneira especial, compreender os mecanismos utilizados por estes homens para manter um elo entre a vida no cárcere e a que viviam fora dele. Vistos numa perspectiva de "escrita de si" (GOMES, 2004), os bilhetes revelam muito sobre o cotidiano dos presos: seus problemas, costumes, privações e angústias.

Palavras-chave: Apenados. Penitenciária. Espaços. Escrita de si.

\section{Introdução}

Durante nossa pesquisa de mestrado pela Universidade Federal do Tocantins (UFT), propusemo-nos a elucidar o ambiente da prisão como digno de atenção científica, não por servir de depósito para indivíduos vitimados e destituídos de poder, mas por ele se tornar cada vez mais um espaço-tempo em que a vida cotidiana se reconfigura por uma cultura

\footnotetext{
* Doutora em História pela Universidade Federal de Pernambuco. É professora do Curso de História da Universidade Federal do Tocantins e dos Mestrados em Ciências do Ambiente e Desenvolvimento Regional na mesma Universidade. E-mail: temis@uft.edu.br

** Mestre em Ciências do Ambiente pela Universidade Federal do Tocantins. Doutorando em Sociologia pela Universidade de Brasília. E-mail: valcelirbs@gmail.com
} 
emergente $^{1}$. Na ocasião, utilizamos o cruzamento de variados processos metodológicos, dentre os quais a análise de 960 bilhetes escritos por presos da Casa de Prisão Provisória de Palmas (CPPP), nosso ambiente de pesquisa.

A riqueza de informações expressa objetiva e subjetivamente nestes bilhetes extrapolou os limites que nos havíamos estabelecido, de modo a merecer de nossa parte uma atenção especial em separado. Assim, pretendemos, neste artigo, fazer uma análise destes bilhetes, que revelam o ambiente da prisão sob o olhar de quem o habita e, por isso mesmo, podem ser considerados como formas de “escrita de si” (GOMES, 2004).

As formas de "escrita de si”, como cartas, bilhetes e e-mails, são cada vez mais utilizadas como instrumento de análise em estudos históricos e sociais por sua proximidade imediata aos fatos ocorridos, denunciados por pessoas diretamente por eles envolvidas. Assim, tornam-se importantes para a melhor compreensão dos processos e fenômenos que se desenvolvem na esfera pública e/ou na particular.

O interesse crescente pelos arquivos privados, neste caso os bilhetes, corresponde a uma mudança de rumo fundamental na história das práticas historiográficas devido ao impulso experimentado pela história cultural $^{2}$ e pela mudança na escala de observação do social, que levou, sobretudo sob a ótica da micro-história, a um interesse ainda maior por fontes qualitativas.

Segundo Prochasson (1998), os cientistas sociais não resistem ao encantamento produzido pelo contato com as fontes primárias, documentos, papéis, fotografias, capazes de revelar parcelas desconhecidas ou até então invisíveis da história e do mundo social. Esta sensação é fortalecida quando o material foge aos rigores institucionais da produção documental, às características seriais e ao estilo formal e burocrático, ou seja, quando é de origem privada e apresenta um caráter pessoal, conferindo a impressão de que se está tomando contato com frações muito íntimas da história e de seus personagens.

O acesso a estes documentos tem a força de simular, no tempo, de forma direta, sem mediações, a imersão na experiência vivida. Muito embora os bilhetes do cárcere não tenham a intenção central de "falar de si”, acabam por revelar muitos aspectos das pessoas que os escrevem e de sua cultura no interior da Casa de Prisão. Assim, podemos classificar estes

\footnotetext{
${ }^{1} \mathrm{O}$ termo emergência diz respeito ao surgimento espontâneo de novidades e novas estruturas complexas a partir de outras mais simples. Este conceito, inicialmente utilizado em pesquisas de sistemas vivos, ganha cada vez mais espaço em estudos de fenômenos sociais. Para mais informações a respeito, cfr. Capra (2005).

${ }^{2}$ A História Cultural é feita de redescobrimentos, de sedimentações, de inércias, isto é, não se sentem as mesmas coisas segundo uma série de critérios: o sexo, a idade, a categoria social, o local geográfico, a tradição, ou a cultura que se recebeu. O historiador da cultura deve sempre tentar entender essa complexidade, essa simultaneidade de atitudes muito diferentes, segundo os indivíduos e segundo os grupos (VIDAL, 2005).
} 
bilhetes como arquivos privados, uma vez que "pendem para o lado da intimidade, na medida em que não foram chamados, no momento de sua elaboração, a atingir um nível de oficialidade ou de notoriedade que caracteriza os dois outros tipos [os arquivos administrativos e as obras]” (PROCHASSON, 1998).

É nesta perspectiva de “descoberta” que visualizamos a riqueza dos bilhetes dos homens presos da СРPP. Por intermédio deles, visamos a compreender seu esforço em manter os espaços ${ }^{3}$ sociais extramuros conquistados anteriormente. A teia de significados e a imensa subjetividade destes “documentos” lançam luz sobre as noções de vários espaços criados e vivenciados pelos prisioneiros no interior da Casa de Prisão.

A partir de uma interpretação dos bilhetes do cárcere, pretendemos compreender como se efetiva a intermediação dos espaços intra e extramuros e quais as estratégias utilizadas pelos prisioneiros para ultrapassarem as barreiras impostas pelas condições sociais em que vivem. De fato, quando o preso chega à Casa de Prisão, há um imediato rompimento com o tempo e com o espaço da maneira como se configuravam antes da prisão, de modo que todas as novas atividades que passam a integrar sua nova vivência cotidiana são radicalmente diferentes, pela mudança da rotina, de hábitos, pela privação de contatos com a sociedade extramuros, transformando seu modo de ser e de viver.

\section{A prisão dos espaços / os espaços da prisão}

[...] a minha vida anterior se diluía, perdia-se além daquele imenso espaço de vinte e quatro horas. Um muro a separar-me dela, altear-se a engrossar, e para cá do muro - nuvens, incongruências. Entre esses farrapos de realidade e sonho, era doloroso pensar numa inteira despersonalização.

Graciliano Ramos

A privação da liberdade em prisão é uma pena que o Estado aplica àqueles que rompem com as normas de conduta socialmente estabelecidas, sendo uma das formas de punição mais conhecidas desde a antiguidade (FOUCAULT, 1997). Como evidenciado por Graciliano Ramos na epígrafe acima, esta privação implica mais que a proibição de circular; na maioria das vezes, significa para o homem preso a perda da própria identidade, ou seja, opera uma verdadeira “despersonalização” em que o tempo para se torna confuso e lento, repetindo-se o tempo todo em um mesmo lugar, delimitado por altas muralhas e grades fortes.

\footnotetext{
${ }^{3}$ Espaços aqui articulados como as representações de diferentes objetos: dos ambientes, das relações, dos valores e das práticas vivenciadas cotidianamente em uma determinada cultura.
} 
Para Goffman, a prisão se configura como uma instituição de extremo grau de fechamento, no qual seus internos seguem uma rotina rigorosa, sob disciplina rígida, podendo por isso ser considerada uma “instituição total”. As instituições totais são “ambientes de residência e trabalho, onde se concentram pessoas, em condições semelhantes, privadas do convívio com a sociedade, por expressivo período de tempo, o que acaba por configurar uma vida fechada e formalmente controlada” (GOFFMAN, 1974, p. 11).

O caráter de “fechamento" das prisões é, ainda segundo Goffman (1974, p. 16), "simbolizado pela barreira à relação social com o mundo externo e por proibições à saída dos internos”. Estas barreiras se configuram não apenas no plano físico, através de "portas fechadas, paredes altas, arame farpado, fossos, água, floresta ou pântanos”, mas também estabelecem múltiplas fronteiras no plano simbólico. Parte destes símbolos é composta por um conjunto de regras que disciplinam a convivência interna entre os presos, caracterizando os espaços sobrepostos no interior da instituição, que se diferenciam pelo que é ou não permitido, por locais por onde se pode ou não circular.

Outro aspecto que caracteriza a prisão é a brusca mudança na relação entre espaço e tempo experienciada pelos homens presos. No ambiente extramuros, pelo fato de o espaço ser demasiadamente amplo, precisa ser fracionado em função de sua utilidade. Assim, há lugares específicos para estudar, trabalhar, dormir, etc. Em contrapartida, o tempo parece comprimido pela correria do dia-a-dia. É comum o homem "livre” contemporâneo ter a sensação de que o tempo passa cada vez mais rápido e que fica cada vez mais difícil cumprir com as obrigações sociais que lhes são exigidas.

No ambiente da prisão ocorre exatamente o inverso: o espaço físico fica reduzido à pequena área da cela, tornando-se, assim, aprisionado juntamente com o homem preso. É neste pequeno recorte espacial que são realizadas todas as possíveis suas ações: o estudo, o lazer, a dormida noturna, as necessidades fisiológicas e até mesmo as atividades mais íntimas. Enquanto isso, o tempo parece passar bem mais devagar; torna-se esvaziado de ações que façam sentido para ele.

Os espaços, sujeitos às mesmas regras por parte da equipe dirigente ${ }^{4}$, podem ser configurados de maneira diferente pelos códigos internos dos prisioneiros. Cada cela, por exemplo, pode dispor de regras próprias que regem a convivência entre seus ocupantes. Mesmo assim, estes espaços são frequentemente vigiados e vistoriados, o que permite à

\footnotetext{
${ }^{4}$ Compõem esta categoria o conjunto de todos os agentes prisionais e outros funcionários da Casa de Prisão, responsáveis pela manutenção da ordem e disciplina entre os presos.
} 
equipe dirigente impor disciplina, manter certo controle sobre as atitudes dos internos e submetê-los a certas condições de vulnerabilidade.

A CPPP não difere de outras Casas de Prisão do Brasil. É uma estrutura montada com amplo esquema de segurança, muros altos, cercas com arame farpado, segurança policial e vigilância 24 horas. A instituição fica localizada na Zona Rural da cidade de Palmas-TO (cerca de 12 quilômetros do marco zero da cidade) e está em funcionamento desde 24 de janeiro de 2002.

A CPPP foi projetada para receber 260 homens, distribuídos em 56 celas simples e 4 especiais (teoricamente destinadas a presos com nível de escolaridade superior), dispostas, igualmente, em dois pavilhões, “A” e “B”. Em 5 de junho de 2009, data de nossa visita ao setor de registros da instituição, o total de homens presos era de 333.

No interior da Casa de Prisão há três espaços delimitados por tarefas específicas, cujos horários de utilização ficam sob controle da equipe dirigente: a cela, o "banho de sol” e o corredor. A cela é o espaço/local onde os presos passam a maior parte do tempo, considerada o ambiente do convívio, ou seja, é o espaço que mais se aproxima do que no extramuros se classificaria como lar. Este espaço é normalmente caracterizado por uma distribuição desigual de poder, que pode ser polarizada, de um lado, pelo “dono” da cela, que impõe regras e distribui tarefas; por outro, pelos presos "corro" 5 , ou que foram condenados por crimes vistos com certa repulsa pela comunidade de presos, como estupro e violência contra crianças.

Normalmente, os presos ficam trancados nas celas; contudo, às segundas e sextasfeiras estas são abertas e a locomoção se torna livre por todo o pavilhão (segundo as regras da equipe dirigente) através do corredor, espaço coletivo intermediário e de passagem que ganha importante valor no contexto da prisão por se tornar um ambiente coletivo e social, onde os detentos podem se comunicar com parceiros de celas diferentes e, com isso, ter acesso a informações, materiais e serviços não-disponíveis no espaço das suas celas particulares.

Outro espaço importante na prisão é a área reservada ao banho de sol, localizada nos fundos dos pavilhões e considerada pelos presos como ambiente social por excelência. É na área do banho de sol que acontecem as atividades coletivas que permitem um aglomerado maior de pessoas, inclusive visitantes, como cultos evangélicos, jogos de futebol, casamentos, batizados de capoeira, entre outras. No momento do banho de sol, os presos aproveitam para

\footnotetext{
${ }^{5}$ Presos recém-chegados.
} 
ver os recém-chegados, jogar bola, jogar capoeira, conversar com companheiros de outras celas, admirar o céu ou simplesmente andar ao acaso de um lado para outro.

O contato dos presos com o espaço externo a estes três ambientes só é realizado de forma indireta, preferencialmente através de correspondências, por cartas ou bilhetes, que ainda precisam passar pela censura da equipe dirigente caso sejam direcionados a terceiros. Se, por qualquer motivo, o preso precisar ir a outros espaços no extramuros, precisa obter uma autorização institucional, como acontece em saídas para tratamento médico-odontológico, participação em atividades laborais, prestação de serviços em espaços externos e recebimento de visitas ${ }^{6}$.

\section{0 que dizem os bimbal $^{7}$}

A disciplina imposta aos homens presos transforma o espaço da prisão em palco de mútua negociação. A equipe dirigente, embora imbuída de autoridade para impor as regras de disciplina aos presos, fica na dependência de como estes se comportam no cumprimento ou não das regras. Para controlar as reações dos presos sobre determinadas ações da equipe, é comum que a comunicação entre eles (presos e equipe) seja realizada através de material escrito em forma de carta, ou mais comumente, de bilhete. Tais correspondências formam uma rede de relações pela qual é possível visualizar o cotidiano e as condições dos presos no espaço intramuros da instituição.

Os bilhetes dos presos, assim como as cartas, são produzidos para um destinatário, aquele com o qual pretende se comunicar, o que implica trocas entre quem escreve e quem lê. Mas os bilhetes e as cartas também apresentam diferenças. Enquanto as cartas possibilitam sempre ao leitor projetar na imaginação uma condição capaz de configurar as cenas descritas e enunciadas pelo conteúdo que apresentam, dando maior liberdade de interpretação ao destinatário, os bilhetes são mais diretos e claros. Suas mensagens precisam ser totalmente compreendidas, por isso apresentam fragmentos de ideias que dispensam contextos mais bem elaborados.

Por outro lado, as cartas, em geral, são mais utilizadas para fazer ligação entre os espaços intra e extramuros, enquanto os bilhetes quase sempre se limitam à circulação interna.

\footnotetext{
${ }^{66}$ Para visitar os presos é necessário que o/a visitante seja autorizado/a, antecipadamente, por superiores da equipe dirigente. No caso das visitas regulares por parte de parentes, principalmente esposas, torna-se obrigatório que a visitante adquira uma carteirinha expedida pela própria Unidade Prisional.

7 "Bimbal” é como os presos e também os funcionários da Casa de Prisão se referem aos bilhetes, podendo considerar-se uma gíria institucional.
} 
Nos bilhetes, diferentemente das cartas, não existe preocupação cronológica, até porque o tempo para os presos normalmente é contado de forma diferente, não pelos dias da semana, do mês ou do ano, mas pela quantidade de dias passados no presídio em referência ao que ainda resta de pena por cumprir.

Outra diferença evidente entre um e outro modo de correspondência está no tipo de material utilizado. Enquanto nas cartas há uma preocupação maior com o tipo de papel, dando-se preferência às folhas pautadas de cadernos ou folhas brancas no formato oficial, os bilhetes podem ser escritos num pedaço de papel de qualquer tipo. Além dos convencionais, são utilizados verso dos autos de processo, sacos de papel, carteira de cigarros, papel higiênico e até mesmo o verso das embalagens de creme dental, como pode ser observado na figura 1, abaixo:

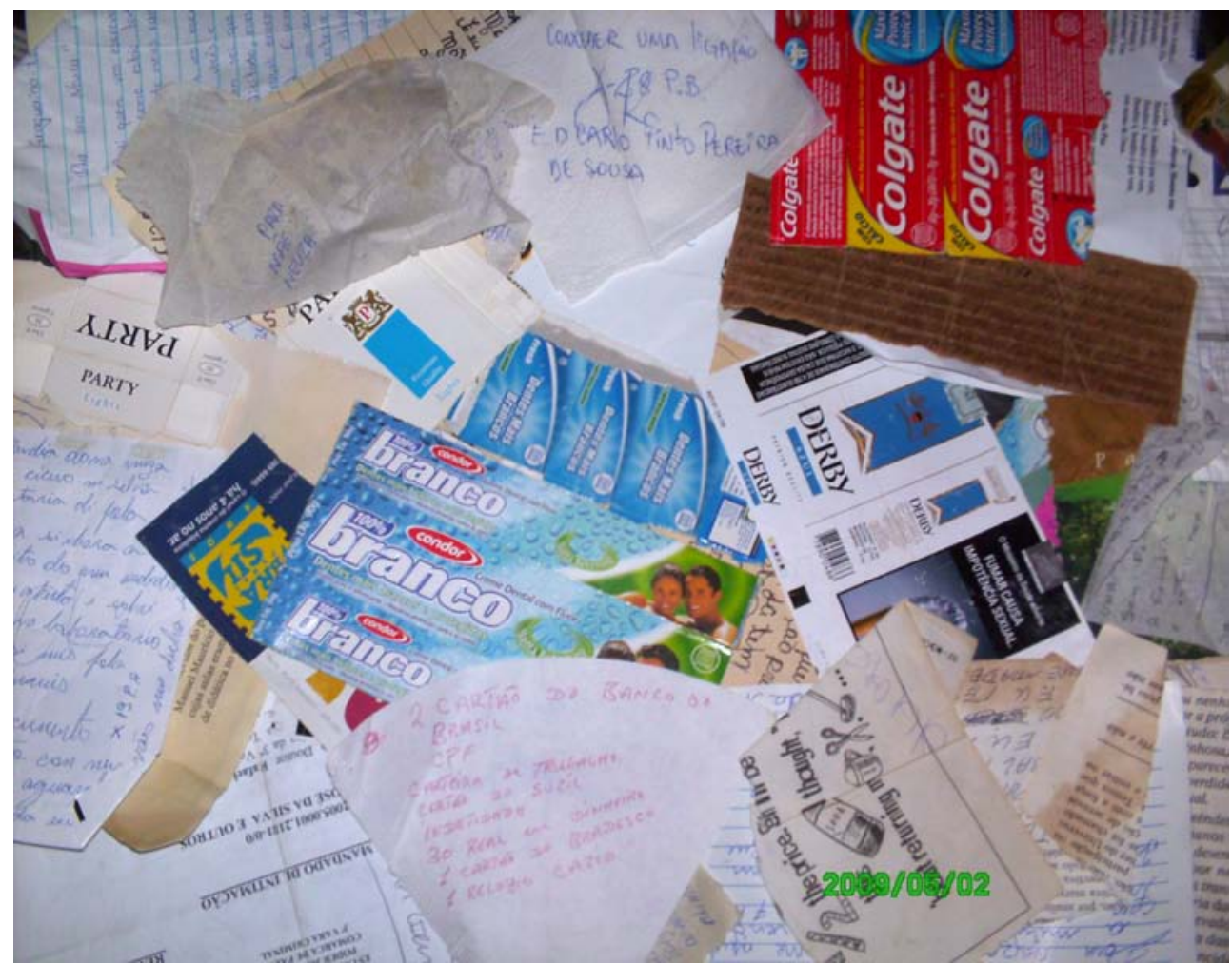

FIGURA 1: Papéis utilizados pelos presos para escrever os bilhetes Fonte:

Tivemos acesso a uma “caixa” que continha 960 destes bilhetes. Nossa intermediária, D. Neuza, pessoa que mantém contato direto com os presos e é responsável por desenvolver o trabalho social na Casa de Prisão. Obtivemos, também, sua autorização para utilizá-los para fins de pesquisa. É raro que os bilhetes sejam datados, mas os que apresentavam data foram escritos entre junho de 2005 e novembro de 2006. O grande volume de bilhetes acumulados em pouco mais de um ano demonstra que representam uma prática bastante utilizada no 
interior da Casa de Prisão e que o mundo do cárcere guarda seus códigos, sua moralidade e dinâmica internas, cujas especificidades não aparecem em qualquer documento oficial.

Os bilhetes do cárcere extrapolam as formalidades oficiais, pois não obedecem a autorizações ou a censuras externas, constituindo um mecanismo intermediário, ou seja, um elo entre as necessidades imediatas dos presos e a única possibilidade "legal” de serem atendidos. Estes bilhetes apresentam uma singularidade: em boa parte dos casos, quem escreve não sabe se será lido, respondido ou atendido, nem mesmo espera uma reposta escrita e/ou oral. Só resta a quem escreve a esperança de ter seu pedido atendido e a eterna angústia da espera:

Bom dia, dona Neusa.

Eu, M. C. da S. que me encontro no PB cela 8.

Venho mais uma vez encarecidamente lhe pedir pra senhora me autorizar uma ligação. A senhora é sabedora que não sou daqui de Palmas. Sou de Araguaína. Pois estou precisando comunicar com a minha família para me trazer algum medicamento que estou precisando. Assim que este bilhete chegar em suas mãos, por favor me mande resposta. Sabendo eu que o meu pedido será aceito.

Humildemente.

M. C. da S. ${ }^{8}$

Obs: Dona Neusa este já é o terceiro bilhete que lhe mando. Por favor, me mande alguma resposta, ok!

Desde já ficarei muitíssimo agradecido.

Neste sentido, os bilhetes do cárcere perdem o caráter livre das correspondências, já que são o único meio disponível, e portanto obrigatório, no contexto da prisão onde aos sujeitos são vetadas outras formas de comunicação com as pessoas para quem necessitam dirigir a mensagem e não estabelecem com elas uma relação de troca de mensagens, mas de mensagens por "favores" que nem sempre se concretizam.

Em solidariedade pela privação de material ou até de domínio da escrita, alguns presos cedem espaço em seus bilhetes a mensagens de outros presos e, às vezes, intercedem pelo amigo junto ao destinatário.

Quando lidos de forma isolada, os bilhetes do cárcere não geram muitos significados; porém, em conjunto, logo aparecem regularidades que revelam uma rede de sentidos e variadas relações afetivas, familiares, curiosas noções de tempo e espaço, de lugar social ocupado pelo missivista, além de experiências cotidianas de toda uma história interna muito pouco ou quase nada conhecida. Por isso mesmo, estes bilhetes são instrumentos ricos para uma análise sociológica do ambiente da prisão.

\footnotetext{
${ }^{8}$ Com exceção da destinatária, que nos autorizou utilizar seu nome, optamos apenas pelas iniciais dos nomes mencionados nos bilhetes.
} 
Podemos analisá-los sob a ótica do lugar social dos sujeitos que os escrevem: que posição social ocupam os missivistas dos bilhetes? Levando em consideração a estrutura de poder externo, sempre sob controle da equipe dirigente, todos ocupam o mesmo lugar social, já que, independentemente de classe social, nível de escolaridade, crime ou credo, se encontram em ambiente fechado, sujeitos às mesmas condições de disciplina e controle. Ainda assim, há presos que no período do cumprimento da sua pena conquistaram maior ou menor apreço por parte da equipe dirigente, o que normalmente está associado a comportamento e à sua capacidade de se mostrar domesticado, docilizado, como tão bem o denunciou Foucault (1997).

No interior da Casa de Prisão, porém, há uma hierarquização dos internos segundo regras específicas de convívio que eles próprios estabelecem, o que explica por que uns possuem mais influências e poder de decisão do que outros e, até mesmo, por que podem impor disciplina e atribuições aos outros. Na maioria das vezes, essa hierarquização não condiz com a realizada pela equipe dirigente. Nem sempre um interno bem considerado pelos dirigentes goza de igual prestígio entre seus companheiros presos, e vice-versa. Por isso, a escrita dos bilhetes se dá numa espécie de negociação entre as regras da equipe dirigente e os arranjos realizados entre os presos.

Os bilhetes dos presos desnudam o ambiente interno do cárcere. Revelam uma pluralidade de vidas, com seus afazeres, necessidades, medos, privações, angústias. Cada linha dos papéis amarrotados, escritos em grande parte com letras disformes e traçados tortos, traduz desabafos, denúncias ou solicitações na tentativa de se sobrepor àquele espaço-mundo configurado em seu cotidiano:

Mãe Neusa; eu W. S. do N. estou precisando muito conversar com a senhora, pois desde que fui recolhido que estou sem nada, não tenho lençol, toalha, roupas, creme de axilas, etc. sem falar na depressão que estou sentindo. Ontem eu escrevi para a senhora, mas o agente me falou que a senhora não estava aí. Mãe Neusa, me ajude pelo amor de Deus. Arrume uma função pra mim tabalhar aí na frente, eu prometo que não irei decepcioná-la nem a senhora, nem a direção [...].

W.

Os bilhetes demonstram que, mesmo sujeito a processos de domesticação, cada indivíduo registra a sua maneira própria de estar no mundo, negociando com os sistemas normativos imediatos através de um dos poucos mecanismos a que tem acesso, para manter o elo entre os espaços intra e extramuros: o individual e o familiar, o real e o simbólico, a prisão e a liberdade. 
Um fato que nos chamou a atenção é a forma de tratamento utilizada para com D. Neusa: todos a tratam por “mãe”, “mamãe”, “mãezinha”, “mãezona”. É neste momento que verifica o que Goffmam (1974, p. 45) denomina de autoridade escalonada: são regras difusas existentes num sistema de autoridade em que "qualquer pessoa da classe dirigente tem direitos para impor disciplina a qualquer pessoa da classe de internados, o que aumenta nitidamente a possibilidade de sanção”.

De certa maneira, os presos parecem ter assimilado as regras difusas e impostas com rigor, sendo possível perceber a angústia quanto às consequências de seu eventual descumprimento. O detento parece compreender que, fazendo o papel do "bom preso", faz aumentar suas chances de ter seu pedido realizado, motivo dos muitos elogios, da educação, da aparência de regenerado, da demonstração de grande afeto pela destinatária:

Palmas - Tocantins, 17/03/06
P/ Mãe Neusa,
Mãe Neusa, eu W. C. de A. venho através deste simples bilhete lhe falar que a
senhora é uma pessoa muito especial pra mim. Eu fiquei um pouco sentido que a
senhora me cobrou uma coisa que eu não sabia, é que a senhora me falou que eu
nem preocupo com a senhora. A senhora estava doente e eu não escrevi pra procurar
se a senhora estava boa ou ruim, então peço desculpa a senhora de eu ser um filho
desleixado com a senhora, também eu quero que a senhora saiba que eu amo muito a
senhora, a senhora pra mim é a minha segunda mãe e uma pessoa muito especial, é
claro que eu iria ficar muito sentido se eu soubesse que alguma coisa de ruim
aconteceu com a senhora [...]. Mãe Neusa eu te amo no fundo do meu coração
mãezinha e eu peço a Deus pra ele te iluminar todos seus passos e que nada de ruim
te aconteça também. Um beijão e um abraço do seu filho que te ama muito.
W. C. de A.

No conjunto dos bilhetes, é clara a introjeção do papel de mãe, tanto de parte dos presos quanto da pessoa que recebe esse tratamento. O papel de mãe, presente no imaginário social, que é de cuidar e gerir as ações dos filhos, é assimilado pelos detentos e também pela equipe dirigente. Para ser aceita e até mesmo institucionalizada como "mãe” dos presos, é necessário que a destinatária não apenas tenha atributos do gênero feminino, mas goze de uma cadeia de significados que espelham nela toda uma história individual e coletiva de vida destes homens, junto aos quais a figura materna recebe lugar de destaque, seja por referência às próprias mães, seja pela privação da convivência com elas.

A construção da identidade materna vai além das estruturas físicas e de poder constitutivas da instituição prisional. Apresentam também aspectos afetivos e identitários das pessoas envolvidas, suas historicidades. Assim, do mesmo modo que a destinatária principal assume, de certa maneira, a identidade de mãe, a maior parte dos presos se identifica com o papel de filho, dependente material e afetivamente. Através dos bilhetes, o tratamento de 
"mãe" deixa transparecer ainda outras dimensões do contexto prisional, como as representações coletivas de alternância de papéis de gênero ${ }^{9}$.

Há também uma inversão no que concerne ao papel social desempenhado pelo homem preso, que, geralmente, sendo pai de família, assumia no espaço extramuros o papel de supridor da casa e das necessidades dos seus filhos. No ambiente da prisão, porém, comportase como filho e suas necessidades precisam ser supridas por outrem. Traços da identidade adulta são momentaneamente substituídos por comportamentos e posturas infantis para conseguir incorporar melhor o papel de filho indefeso que precisa de ajuda da mãe:

Mãezinha Neusa,

Seja boazinha comigo. Eu estou nas suas mãos, permite para mim uma ligação, é coisa séria, estou angustiado. Facilita alguma coisa pra mim, seja bondosa atendendo o meu pedido, faça essa força.

S. P. R.

Mãe Neusa, a senhora sabe que eu amo muito a senhora.

Estou rodado aqui, precisando muito da sua ajuda de mãe.

Por favor, mande um kit rodado ${ }^{10}$ pra mim. O que veio já acabou e não tenho nada, tô sem até pasta de dente.

J. O. S

\section{Uma classificação possível}

No que se refere ao conteúdo explícito, dividimos os bilhetes em quatro categorias para análise. É importante ressaltar que eles nem sempre se encaixam em apenas uma das categorias, podendo figurar em diversas. Por outro lado, a classificação é influenciada, de certa forma, pelo fato de os bilhetes serem encaminhados a uma mesma destinatária com função específica na Casa de Prisão, o que acaba por determinar certa homogeneização no tratamento dos assuntos dos bilhetes.

A primeira categoria é formada por bilhetes que contêm desabafos e reclamações. Nestes, os presos geralmente se manifestam angustiados, depressivos, com necessidade urgente de alguém para os ouvir, aconselhar e resolver problemas de ordem prática do convívio nas celas:

\footnotetext{
${ }^{9}$ Papéis de gênero aqui entendidos como comportamentos e atitudes socialmente esperadas pelos membros de uma sociedade, diferenciados por sexo, pois falar de papéis de gênero é falar de padrões, regras que uma dada sociedade estabelece para com os seus membros (PARENTE, 2007).

${ }^{10}$ Os presos utilizam a expressão para se referir ao conjunto de componentes básicos de higiene pessoal, composto de sabonete, sabão para lavar roupa, creme dental e papel higiênico.
} 
Dona Neusa, bom dia!

Preciso da ajuda da senhora.

Por favor, preciso falar com a senhora em particular, ou com uma psicóloga. Estou muito mal, com pensamentos ruins.

Me ajude, por favor. Já não acredito nem em Deus mais.

Só preciso falar com alguém.

Por favor, me tire por alguns minutos daqui.

Por favor.

L.

Bom dia.

Venho através deste bimbal, sra ${ }^{\mathrm{a}}$. Neusa. Eu G. S. A, preso no artigo 155, condenado a uma pena de 4 anos e dois meses inicial semi-abeto e já estou cumprindo 11 meses, e de acordo com o artigo 122 o réu primário tem direito ao trabalho externo e saída temporária com um sexto da pena já cumprida e eu já goso todos os direitos, por isso peço a senhora que me ajude, pois eu mesmo não tenho família neste estado e preciso muito que a senhora me ajude pois não conheço ninguém neste estado e só posso contar com a boa vontade da senhora. Quem mais pode me ajudar? Desde já fico muito agradecido e muito grato. E aguardo resposta.

G. S. A.

Em alguns bilhetes deste grupo, os presos apresentam denúncias, como a alegação de já estar com “tempo de cadeia vencido", ter direito de progressão ao regime semiaberto e permanecer no fechado, não dispor de materiais de uso pessoal, entre outras. É também comum encontrar reclamações por dividirem a cela com um número grande de pessoas, não disporem de colchões para dormir e dividirem cela com colegas que apresentam doenças contagiosas:

\begin{abstract}
Dona Neusa
Venho através deste fazer alguns pedidos para a senhora, pois sei que podes me ajudar.

Dia 21/03 fará 5 meses que estou aqui, nunca ganhei um colchão, se eu quis ter um eu tive que comprar aqui dentro, e o mesmo está mais fino que uma folha de papelão, estou gripado já tem mais de dois meses e não sara por causa da friagem que pego nas costas, gostaria que a senhora me mandasse um colchão novo eu passo até vergonha quando minha visita chega aqui, pois o colchão é muito desconfortável, e o outro pedido é que estou com um dente doendo já mandei vários recados pedindo pra ir no dentista, se eu tomo água dói, comida quente dói, parece que as pessoas aí da direção acha que nós não sentimos dor que nós somos feitos pra agüentar tudo, dor, maus tratos, constrangimentos, humilhações etc [...].
\end{abstract}

S. S. M.

[...]. Nossa ilustre, eu A. já estou com as mesmas manchas que está neste L. G.. Olha nós já avisamos que este problema deste cara é sério e vocês estão duvidando. Olha já avisamos que vamos jogar ele fora da cela. Por causa deste sintoma já estamos todos pestiados. Olha não tem como ele ficar deste jeito junto com nós. Vamos aguardar até o banho de sol.

A. O.

A segunda categoria é composta por pedidos de ligação telefônica. Aqui encontramos uma quantidade imensa de bilhetes. Quase todos se referem à família, seja por motivos de 
saudade, aniversário de filhos, seja de preocupação, como a de um recluso preso quando a esposa estava nos últimos dias de gravidez, o qual argumenta ainda não saber se tudo ocorrera bem no parto, nem saber do sexo do bebê. Grande parte dos presos é de outros estados. Alguns argumentam que a família ainda não sabe de sua prisão em Palmas.

O destino das ligações revela, com a diversidade de locais de origem dos prisioneiros, uma geografia bem ampla de todas as regiões do Brasil:

Doa Neuza, por favor, não me esqueça de me tirar amanhã.

Eu quero falar com meu filho pra desejar o feliz aniversário,

Eu gostaria de proporcionar um momento de alegria a ele,

Já que não posso estar junto dele.

Muito obrigado!

A. P.

Bom dia, D. Neusa.

Só a senhora pode me ajudar. Não sou daqui, sou de São Paulo. Faz mais de mês que fui preso e até agora não consegui uma ligação pra minha família.

Quando saí de São Paulo minha mulher tava grávida e minha mãe tava doente e eu não tenho notícias delas. Elas nem sabem que eu estou preso.

Preciso de uma ligação pra minha família, por favor.

Deus abençoe a senhora.

L. A.

São curiosos os recursos utilizados para garantir o contato com seus familiares: muitas vezes, falam o assunto e pedem para a destinatária ligar, ou seja, têm dúvidas se serão chamados para presenciar a ligação; por isso, diminuem as dificuldades, pedindo que ela própria ligue e fale por eles:

Dona Neusa, ligar pra minha esposa e ver se ela melhorou. Fala pra ela manter a calma e tomar os remédios direitinho pra não perder a criança e quanto mais quieta ela ficar melhor. Evitar ter preocupações. Fala pra ela que to orando por ela e as crianças, em breve esse sofrimento vai acabar. Se ela não manter a calma a criança pode nascer com seqüelas. Fiquei triste em saber que ela ta passando mal. Beijos pra ela, amo muito.

A. P. da S.

Há ainda solicitações dos presos por ligações a advogados, amigos próximos e/ou outras pessoas que possam fazer-lhes algum tipo de favor, quase sempre associado ao andamento do seu processo criminal ou à concessão de bens materiais para uso na prisão.

Em uma terceira categoria, juntamos os bilhetes com solicitação de alimentos e outros materiais. Neste grupo, normalmente os presos pedem à destinatária para entrar em contato com a pessoa responsável por trazer os alimentos e/ou outros materiais e passar a listagem dos produtos para serem adquiridos e trazidos à Casa de Prisão. Torna-se interessante observar a 
variedade alimentar dos presos: enquanto uns pedem que suas famílias tragam "farinha de puba”, "rapadura” ou "massa para cuscuz" ${ }^{11}$, outros solicitam que tragam "lasanha”, "pizza” ou algumas comidas típicas de sua região de origem que exigem um preparo mais refinado:

Palmas-TO, 09/03/06

Bom dia mãe Neusa. Estou te escrevendo para lhe pedir um favor. Ligar para minha irmã e pedir pra ela trazer cobal pra mim. Na visita ela me pediu para fazer uma lista, aqui vai: bolachas, salsichas de cachorro quente, suco, leite, café, açúcar, maionese, sabão em pó e em barra. Peça a ela pra trazer bastante bolachas e bastante suco. P/ ela trazer também um refrigerante. [...] . Fale pra minha irmã comprar uns salgados e mandar pra mim. Parabenize minha irmã pelo dia da mulher que foi ontem e lembre a ela que amanhã é meu aniversário 10/03. Pra mim tudo que ela tem sido e feito por mim é um grande presente. Diga que a amo muito. Deus te abençoe mãe Neusa!

L. A.

[...] $\mathrm{DN}^{\mathrm{a}}$ mãe neuza eu esqueci de te falar se tem como a senhora conseguir 3 kits rodado para nós, por que os que mandaram já acabou e nos estamos sem nem pasta de dente, nem sabonete, nem sabão e nem papel higiênico.

Muito Obrigado!! X-23 Ass: W. B. G de O.

$\mathrm{Na}$ relação de bens materiais e de higiene, a lista pode incorporar desde os componentes do Kit rodado ${ }^{12}$ até itens de uso diverso, como certos tipos de remédios, materiais para confecção de artesanato. Esta categoria permite conhecer os hábitos de higiene e situações de conforto e/ou privações vivenciadas pelos presos. Solicitam sabão para tomar banho e lavar roupas, peças de roupas e calçados, inseticidas e raticidas, embora alguns destes produtos sejam de entrada proibida na Casa de Prisão. Um pedido bastante frequente nestes bilhetes é por cigarros, fato explicado por constituir a principal moeda de troca entre os presos.

Ainda podemos constatar uma listagem de eletroeletrônicos, como aparelhos de som, televisões, DVD, tomadas, entre outros. Muitas vezes, os detentos argumentam que esses objetos chegam à portaria do presídio, mas não são encaminhados às suas celas:

Neusa,

Peço a você por favor para ligar para [...] pedir para a D. trazer para mim uma cobal com: sabão em pó, kiboa, desinfetante, papel higiênico, 3 carteira de cigarros, bolacha mabel, 1 cx. De bombom, refrigerante guaraná, frutas, 1 ventilador, 1 T para tomada, 1 extenção, 1 doce marmelada.

V. R. de O.

Mãe Neusa. Vê pra mim por que meu DVD não entrou.

\footnotetext{
${ }^{11}$ Os presos preparam o cuscuz através de instrumento improvisado com fios metálicos, que chamam de perereca, a qual, ligada à rede elétrica, aquece a água.

${ }^{12}$ Kit de higiene pessoal disponibilizado pela Casa de Prisão contém sabonete, creme dental e papel higiênico.
} 
Minha esposa já deixou faz tempo ai na frente.

Obrigado.

A última classificação possível desses bilhetes foi a de solicitação de oportunidade para trabalho ou estudo. Neles, os presos alegam estar ociosos, já terem cumprido tempo considerável da pena de prisão, como também necessitar de remissão ${ }^{13}$ da pena. O pedido de trabalho que predominantemente aparece tem relação com três fins específicos: a fuga da rotina ociosa das celas, o auxílio financeiro às famílias e a remissão de pena. Nos casos de pedido de estudo, acrescem a necessidade de autonomia com relação à leitura e à escrita exigidas em ocasiões específicas da vida cotidiana e à possibilidade de dar continuidade aos estudos interrompidos no extramuros. A escola ${ }^{14}$ aparece em alguns bilhetes como oportunidade de mudança de vida. Vários presos rogam por uma chance de estudar na escola; falam de seus propósitos de continuar os estudos e da falta de oportunidades para estudar quando estavam no "mundo lá fora”.

Os bilhetes analisados são, normalmente, os mais bem escritos e muitas vezes mais formais, tendo em vista o tratamento adotado por todos eles: "prezada”, “vossa senhoria”, “ilustre”. Além disso, apresentam maior preocupação com o tipo de papel em que são escritos, com o uso das normas de ortografia e com a caligrafia:

Palmas, 27/06/05

Bom dia Sra Neusa!

Após saudá-la cordialmente eu, J. A. do V., reeducando deste estabelecimento penal, venho com muita humildade e no devido respeito, pedir vossa generosa ajuda. [...]. gostaria muito de poder estudar, concluindo até o fim tal meta, desejo trabalhar para facilitar mais as despezas para minha família e ao mesmo tempo poder juntar um dinheirinho enquanto aqui estou, pois um dia irei sair não é mesmo? Então irei precisar, pois lá fora são muito difíceis as coisas.

[...] existe esta tal mudança para o presídio de Araguaína, eu não tenho conhecimento se vou ou não. Mas acho particularmente que a mais necessária mudança seja na parte interna do coração, no próprio querer de cada um, e isso já ocorreu comigo. [...]

Eu espero que esteja no alcance de vossa pessoa me ajudar nesses três sentidos: Estudo, serviço, permanência. Pois se não for possível gostaria de tomar conhecimento anterior para que eu possa batalhar pela transferência para o Goiás.

Humildemente,

J. A. do V.

Palmas-TO, 15/03/06

Boa tarde mãe Neusa. Venho através deste fazer-lhe um pedido, um favor; eu mandei alguns bilhetes para o Sr. F. e para a $\mathrm{Sr}^{\mathrm{a}}$. S. comunicando-lhes o meu interesse de trabalhar e ganhar remissão. Sou condenado a 10 anos e 3 meses.

\footnotetext{
${ }^{13}$ A remissão de pena é a troca de três dias trabalhados por um dia remido em sua pena. Na CPPP, a remissão também é concedida, na mesma razão, a presos que estudam que aos que trabalham.

${ }^{14}$ Escola Estadual Nova Geração, interna à CPPP, e em funcionamento desde 28/02/2005.
} 
Preciso da ajuda de vocês. Não importa o setor de trabalho, o que quero é a oportunidade de trabalhar. Vê pra mim mãe neusa a possibilidade minha de trabalhar e ganhar remissão. Deus te abençoe!

L. A.

\section{Algumas considerações}

Procuramos, neste trabalho, utilizar os bilhetes escritos pelos presos da CPPP a fim de compreender os mecanismos por eles utilizados para superar as limitações impostas pelas condições da prisão, de modo a manter o elo com os espaços intra e extramuros. Inicialmente, delimitamos o ambiente da prisão que constitui o espaço multifacetado de fala dos emissários para, posteriormente, apresentar uma categorização e análise de tais bilhetes.

A prisão, como argumentamos, interpõe entre o homem preso e o meio social extramuros barreiras físicas intransponíveis. Elas impedem aos presos de realizar ações cotidianas como as que exerciam na sociedade extramuros, em particular as derivadas dos papéis sociais de pai, esposo, trabalhador, entre outros.

Os bilhetes do cárcere se inserem neste contexto como a única oportunidade de manterem relações sociais com o mundo externo; para que isso ocorra de maneira satisfatória, torna-se necessária certa inversão de papéis, uma vez que na prisão eles assumem a condição, imprescindível para manter esse elo, de filhos, submissos, dependentes.

$\mathrm{Na}$ análise dos bilhetes, foi possível levantar as condições de encarceramento que expõem os presos a situações tão adversas a ponto de uma simples ligação para a família ou a ida ao médico precisar da intermediação de outrem, neste caso “mãe Neuza”, que assume um papel legalmente instituído para a função. Os bilhetes do cárcere representam algum tipo de possibilidade de transposição destas limitações entre os detentos e suas necessidades imediatas, como também são reveladores de suas angústias, privações, carências. Os bilhetes tornam-se, assim, instrumentos ricos de interpretação. Por eles, é possível conhecer a cultura prisional vivenciada por esses emissários de bilhetes e o mundo extramuros tão sonhado por eles. 


\title{
NOTES FROM PRISON: link between spaces
}

\begin{abstract}
The penitentiary world has been the object of a variety of studies in the most diverse areas of knowledge and still maintains itself poorly understood. This is due particularly to the barriers that are imposed to the researchers in the gaining of direct contact with prisoners and primary data sources. In this sense this work, developed during the Master dissertation studies in Environment Sciences in the Federal University of Tocantins (UFT), presents a plus in the analysis by including 960 notes written by men held in prison, in the provisory detain house of Palmas. The purpose of this article is to present an interpretation of the quotidian life in prison by means of interpretation of note readings written by the inmates. In a unique manner, we tried to understand the mechanisms used by these men to maintain a link between life in prison and the one external to it. Seen in a self perspective of writing (GOMES, 2004), the notes reveal much of the quotidian of prisoners in the house of prison: their problems, conduct, privations and anguishes.
\end{abstract}

Keywords: Prisoners. Penitentiary. Spaces. Self writing.

\section{Referências}

CAPRA, Fritjof. As conexões ocultas: ciência para uma vida sustentável. São Paulo: Cultrix, 2005.

GOMES, Ângela de Castro (Org). Escrita de si, escrita da história. Rio de Janeiro: Editora FGV, 2004.

VIDAL, Laurent. Alain Corbin, o prazer do historiador. Revista Brasileira de História, São Paulo: Associação Nacional de História, janeiro/junho, v. 25, n. 49. 2005. p.11-31.

HEYMANN, Luciana Quillet. Indivíduo, memória e resíduo histórico: uma reflexão sobre arquivos pessoais e o caso Filinto Muller. Estudos Históricos, Rio de Janeiro, n. 19, 1997. p. 41-67.

GOFFMAN, Erving. Manicômios, prisões e conventos. São Paulo: Perspectiva, 1974.

FOUCAULT, Michel. Vigiar e Punir: nascimento da prisão. 15. ed. Petrópolis : Vozes, 1997.

PARENTE, Temis Gomes. Gênero e memória de mulheres desterritorializadas. Artcultura: Uberlândia, v.9, n.14, jan/jun 2007. p. 105.

PROCHASSON, Christophe. "Atenção: Verdade!”Arquivos Privados e Renovação das Práticas Historiográficas. Revista Estudos Históricos, São Paulo, v. 11, n. 21, 1998. p. 105120.

Recebido em: Junho/2010

Aprovado em: Agosto/2010 